\title{
Micropropagação de plântulas de erva-mate obtidas de embriões zigóticos
}

\author{
Micropropagation of holly plantlets obtained from zygotic embryos
Micheli Angélica Horbach ${ }^{\mathrm{I}}$ Dilson Antônio Bisognin ${ }^{\mathrm{II}}$ Paula Kielse Kenia Michele de Quadros ${ }^{\mathrm{I}}$ Tiago Antonio Fick ${ }^{\mathrm{I}}$

\section{RESUMO}

\begin{abstract}
O objetivo deste trabalho foi avaliar o potencial de micropropagação de erva-mate (Ilex paraguariensis Saint Hilaire) a partir de plântulas assépticas oriundas de embriões zigóticos imaturos. Ápices caulinares foram inoculados em meio base, formado por $1 / 4$ da concentração dos sais do meio MS, com diferentes doses de 6-benzilaminopurina (BAP). Ápices caulinares foram enraizados em meio base com diferentes doses de ácido indolbutírico (AIB) e avaliado o efeito do AIB do meio de enraizamento in vitro na aclimatização das plantas. $O$ meio base com $8,88 \mu M$ de BAP foi o mais efetivo para a multiplicação, promovendo o maior número e comprimento de brotações adventícias. Ápices caulinares enraizaram em 30

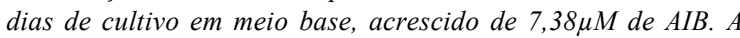
dose de AIB utilizada no enraizamento in vitro interfere na aclimatização das plantas. A técnica de micropropagação descrita pode ser utilizada para a produção massal de plantas de erva-mate.
\end{abstract}

Palavras-chave: Ilex paraguariensis, biotecnologia, multiplicação in vitro, enraizamento in vitro, aclimatização.

\section{ABSTRACT}

The aim of this research was to evaluate the micropropagation potential of holly (Ilex paraguariensis Saint Hilaire) aseptic plantlets derived from immature zygotic embryos. Shoot tip were inoculated in a quarter-strength MS basal medium with different doses of 6-benzylaminopurine (BAP) to induce multiple shoots. Shoot tips were inoculated in a basal medium with different doses of indol-butiric acid (IBA) for in vitro rooting and to test their effects in plantlet acclimatization. The addition of $8.88 \mu \mathrm{M}$ BAP to the basal medium increased the number of adventitious shoots and shoot height. Shoot tip rooted in basal medium with $7.38 \mu M$ IBA in 30 days of culture. The IBA doses of the rooting medium affect plantlet acclimatization. The described micropropagation protocol might be used to produce a high number of holly plants.

Key words: Ilex paraguariensis, biotechnology, in vitro multiplication, in vitro rooting, acclimatization.

\section{INTRODUÇÃO}

A erva-mate (Ilex paraguariensis Saint Hilaire) pertence à família Aquifoliaceae, que compreende mais de 500 espécies do gênero Ilex (HU, 1989), e é uma espécie arbórea que ocorre no Brasil, Argentina, Uruguai e Paraguai (CARVALHO, 2003). As mudas comerciais de erva-mate são produzidas a partir de sementes (WENDLING, 2004), de baixa qualidade genética, física e fisiológica (STURION, 1988). Além disso, as sementes das espécies do gênero Ilex apresentam dormência embrionária, que dificulta o processo de produção de mudas (SANSBERRO et al., 1998; CARVALHO, 2003), sendo necessário um período de estratificação em areia, por um período de cinco a seis meses (ZANON, 1988; FOWLER \& STURION, 2000).

A micropropagação via organogênese direta é comumente utilizada na cultura de tecidos de plantas (KITTO, 1997), sendo que plântulas originadas de embriões zigóticos podem ser uma ótima fonte de

'Programa de Pós-graduação em Engenharia Florestal, Universidade Federal de Santa Maria (UFSM), Santa Maria, RS, Brasil.

"Departamento de Fitotecnia, Centro de Ciências Rurais, UFSM. Av. Roraima, 1000, Bairro Camobi, 97105-900, Santa Maria, RS, Brasil. E-mail: dilsonb@smail.ufsm.br. Autor para correspondência. 
explantes, devido à natureza juvenil dos propágulos, $\mathrm{o}$ que possibilita um maior poder regenerativo dos tecidos (HU \& FERREIRA, 1998). Portanto, o cultivo in vitro de embriões zigóticos é uma excelente alternativa para superar a dormência e reduzir o tempo para a germinação das sementes, o que acelera a propagação de espécies com dormência embrionária (HU, 1989).

O sucesso da micropropagação pode ser influenciado por diversos fatores. O genótipo, o tipo e o tamanho do explante, o meio de cultura e as doses de fitorreguladores são os principais controladores da morfogênese in vitro (MOREIRA-DIAS et al., 2001). Outro fator a ser considerado é a adequação gradual das características físicas e fisiológicas das plantas micropropagadas às condições ex vitro, pois o ambiente encontrado in vitro é consideravelmente diferente das condições presentes em casa de vegetação e no campo, o que promove um alto grau de estresse e pode resultar na morte das plantas durante a aclimatização (HAZARIKA, 2003).

A aclimatização é limitante para a maior parte das espécies micropropagadas, devido à alta taxa de mortalidade. O sucesso da aclimatização depende, em grande parte, da habilidade da planta de passar da condição heterotrófica para a autotrófica, dos fatores abióticos (umidade relativa, temperatura, luminosidade, substratos, entre outros), dos fatores bióticos (pragas e doenças), e da presença ou capacidade das plantas de produzir novas raízes (PAIVA \& OLIVEIRA, 2006).

O objetivo deste trabalho foi avaliar o potencial de micropropagação de erva-mate a partir de plântulas assépticas oriundas de embriões zigóticos imaturos, através da multiplicação e do enraizamento in vitro dos explantes e da aclimatização em substrato.

\section{MATERIAL E MÉTODOS}

Os experimentos foram conduzidos no Núcleo de Melhoramento e Propagação Vegetativa de Plantas, do Departamento de Fitotecnia, da Universidade Federal de Santa Maria, RS. Para o início dos experimentos, plântulas de erva-mate foram obtidas pelo cultivo in vitro de embriões zigóticos imaturos. Ápices caulinares foram então multiplicados, enraizados e aclimatizados, conforme descrito a seguir. O meio de cultura base foi o MS (MURASHIGE \& SKOOG, 1962) com $1 / 4$ da concentração dos sais, acrescido de $3 \%$ de sacarose, $0,65 \%$ de ágar e $\mathrm{pH}$ ajustado para 5,7. Aproximadamente $30 \mathrm{~mL}$ de meio foi adicionado a frascos de vidro de $150 \mathrm{~mL}$, cobertos com papel alumínio e vedados com filme de polivinilcloreto (PVC). Todos os cultivos foram mantidos em sala de crescimento com a temperatura de $25^{\circ} \mathrm{C} \pm 3^{\circ} \mathrm{C}$ e fotoperíodo de $16 \mathrm{~h}$. A intensidade luminosa foi de aproximadamente $14,3 \mathrm{mM} \mathrm{m}^{-2} \mathrm{~s}^{-1}$, obtida por lâmpadas brancas fluorescentes.

Para o estabelecimento in vitro, sementes de erva-mate foram imersas em água destilada por $24 \mathrm{~h}$. A desinfestação foi realizada pela imersão em álcool $70 \%$ por $5 \mathrm{~min}$, seguido da imersão em solução de hipoclorito de sódio $(\mathrm{NaOCl})$ a $2 \%$, acrescida de duas gotas de tween $20^{\circledR}$, por $30 \mathrm{~min}$. Após, as sementes foram submetidas a cinco enxágues com água destilada e autoclavada e, com o auxílio de microscópio estereoscópico, foi realizada a excisão dos embriões, conforme descrito por HU (1989). Os embriões foram inoculados no meio de cultura base, acrescido de 0,044 $\mu \mathrm{M}$ de 6-benzilaminopurina (BAP) (SANSBERRO et al., 1998). Os frascos, com um embrião cada, permaneceram por 60 dias em sala de crescimento, sendo os primeiros 14 dias no escuro. As plântulas de erva-mate oriundas dos embriões zigóticos foram submetidas a três subcultivos em meio de cultura base.

Para a multiplicação in vitro, ápices caulinares de 0,8 a $1,0 \mathrm{~cm}$ de comprimento foram excisados das plântulas e inoculados em meio de cultura base, acrescido de $0 ; 0,44 ; 4,44$ ou $8,88 \mu \mathrm{M}$ de BAP. Aos 50 dias de cultivo, foram avaliados o comprimento $(\mathrm{cm})$ e o número de brotações, entrenós e folhas. O delineamento experimental foi o inteiramente casualizado, com quatro repetições de cinco frascos com um explante.

Para os experimentos de enraizamento in vitro foram também utilizados ápices caulinares de 0,8 a 1,0cm de comprimento, excisados de brotações cultivadas em meio base com $8,88 \mu \mathrm{M}$ de BAP. No primeiro experimento, foram avaliados as concentrações do ácido indolbutírico (AIB) e os tempos de exposição dos explantes ao meio de enraizamento. Os tratamentos consistiram de três doses de $\operatorname{AIB}(0 ; 4,92$ ou 7,38 $\mu \mathrm{M})$ e dois tempos de exposição dos explantes (15 dias em meio com AIB seguido de 15 dias em meio sem AIB ou 30 dias em meio com AIB). Aos 30 dias de cultivo, foram avaliados as porcentagens de enraizamento e formação de calo, o número e o comprimento $(\mathrm{cm})$ de raízes, o número de folhas e o comprimento $(\mathrm{cm})$ das brotações. Os tratamentos foram distribuídos em um fatorial $(2 \times 3)$ no delineamento inteiramente casualizado, com quatro repetições de quatro frascos com um ápice caulinar.

No segundo experimento, foram avaliadas doses maiores de AIB com a exposição dos explantes por 30 dias ao meio de enraizamento in vitro. Os ápices caulinares foram inoculados em meio base acrescido de $0 ; 7,38 ; 14,76$ ou $29,52 \mu \mathrm{M}$ de AIB. Foram avaliadas as porcentagens de enraizamento e formação de calo, o número e o comprimento $(\mathrm{cm})$ de raízes por explante 
aos 30 dias de cultivo. O delineamento experimental foi o inteiramente casualizado, com quatro repetições de quatro frascos com um ápice caulinar.

O efeito das doses de AIB na aclimatização dos ápices caulinares enraizados in vitro foi avaliado no substrato casca de coco em pó, definido em experimento preliminar. Para tal, ápices caulinares enraizados em meio de cultura base acrescido de $0 ; 7,38 ; 14,76$ ou $29,52 \mu \mathrm{M}$ de AIB, com no mínimo três pares de folhas, foram retirados dos frascos, as raízes lavadas em água corrente e submetidos a aclimatização. Cada planta foi transferida para um copo plástico de $200 \mathrm{~mL}$, contendo casca de coco em pó, autoclavada a $121^{\circ} \mathrm{C}$ por $45 \mathrm{~min}$. As unidades foram irrigadas três vezes por semana com água destilada e uma vez por semana com $1 / 4$ dos sais do MS. As unidades foram mantidas em sala de crescimento por 30 dias, sendo os primeiros 15 dias cobertas com filme de PVC e nos 15 dias restantes sem o filme de PVC, sendo então transferidas para a casa de sombra. Aos 30 dias em casa de sombra, foram avaliados as porcentagens de sobrevivência, o enraizamento e a formação de calos, o número de raízes e a altura $(\mathrm{cm})$ das plantas. O delineamento experimental foi o inteiramente casualizado, com quatro repetições de cinco plantas.

Os dados foram submetidos à análise de variância, e as médias comparadas pelo teste de Tukey (dados qualitativos) ou análise de regressão (dados quantitativos). Para a análise, os dados de porcentagem foram transformados para arco seno $\sqrt{x / 100}$ e de contagem e comprimento para $\sqrt{x+0,5}$.

\section{RESULTADO E DISCUSSÃO}

$\mathrm{Na}$ multiplicação, explantes de erva-mate produziram brotações em meio com $1 / 4$ da concentração dos sais do MS, mesmo na ausência de BAP. Entretanto, a adição de BAP ao meio base aumentou o número de brotos, de entrenós e folhas e o comprimento das brotações (Figura 1A e 1B). Além disso, brotações

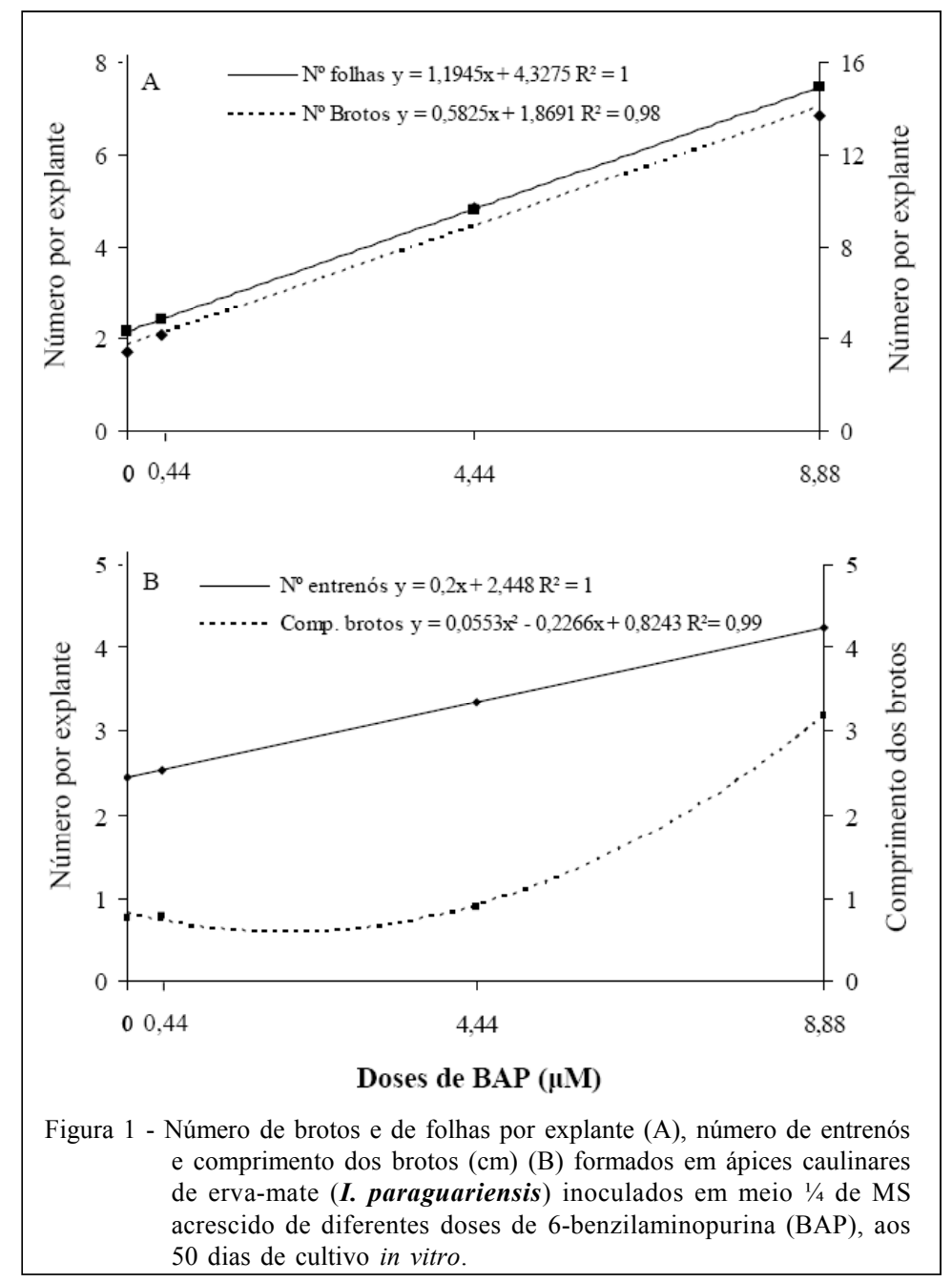

Ciência Rural, v.41, n.1, jan, 2011. 
múltiplas foram formadas a partir de explantes cultivados em meio base contendo $8,88 \mu \mathrm{M}$ de BAP, o que está de acordo com os resultados obtidos por outros autores para esta espécie (PAULA, 1992; ZANIOLO \& ZANETTE, 2001). SANSBERRO et al. (1999) também verificaram a formação de brotações, mesmo quando segmentos nodais de erva-mate foram inoculados em meio de cultura sem a adição de fitorregulador, porém a adição de BAP aumentou o número e o comprimento das brotações até a dose máxima utilizada de $4,44 \mu \mathrm{M}$.

Uma das vantagens de se utilizar explantes oriundos de embriões zigóticos é a alta juvenilidade e capacidade de regeneração que apresentam, podendo ser facilitada pela adição de citocininas ao meio de cultura, como ocorrido neste trabalho, com a adição de $8,88 \mu \mathrm{M}$ de $\mathrm{BAP}$, que promoveu o aumento do número e comprimento dos brotos produzidos. Além disso, as plântulas fornecedoras dos ápices caulinares podem ser mantidas in vitro para produzir novas brotações e aumentar a taxa de multiplicação, como verificado em louro-pardo (Cordia trichotoma Vell.) (FICK et al., 2007). Apesar da espécie estar sujeita à oxidação fenólica, especialmente quando os explantes são oriundos de material adulto (WENDLING, 2004; DUTRA et al., 2008), isso não foi observado neste experimento, o que pode ser atribuído à natureza juvenil dos propágulos e até aos genótipos utilizados.

No primeiro experimento de enraizamento in vitro, houve interação entre a dose de AIB e o tempo de exposição dos ápices caulinares de erva-mate à auxina para a porcentagem de enraizamento e o comprimento de raízes e brotações (Tabela 1) e não houve interação para a porcentagem de calo e o número de raízes e folhas (Tabela 2). A adição de AIB e o cultivo dos ápices caulinares por 30 dias no mesmo meio de cultura aumentou a porcentagem de enraizamento e o comprimento de raízes e brotações (Tabela 1). O cultivo dos ápices caulinares de erva-mate por 30 dias em meio de cultura com AIB também aumentou o número de raízes e de folhas (Tabela 2). A adição de AIB ao meio de cultura base aumentou a porcentagem de calo e o número de raízes, sem afetar o número de folhas.

Alguns estudos sugerem que o enraizamento de brotos de erva-mate seja realizado em duas fases, para se aumentar o número de raízes formadas (PAULA, 1992): a primeira, de indução, em que os explantes permanecem em meio de cultura com 7,38 ou $14,76 \mu \mathrm{M}$ de AIB; e a segunda, de crescimento das raízes, realizada em meio sem a adição de AIB (SANSBERRO et al., 1999; ZANIOLO \& ZANETTE, 2001). Neste experimento, tanto a adição de AIB ao meio de cultura base quando o cultivo por 30 dias no mesmo meio foram necessários para aumentar o número de raízes (Tabela 2) e o comprimento das raízes (Tabela 2). Portanto, o enraizamento in vitro de ápices caulinares de erva-mate pode ser realizado em meio de cultura base acrescido de 4,92 ou 7,38 $\mu \mathrm{M}$ de AIB e em apenas uma fase, o que reduz o número de manipulações dos explantes e o consumo de material.

O segundo experimento de enraizamento in vitro também evidenciou a necessidade de adição de AIB ao meio de cultura base, mesmo de ápices caulinares que apresentavam uma porcentagem de enraizamento de $41 \%$ sem auxina (Figura 2A). A adição de AIB ao meio de cultura base mais que dobrou a porcentagem de ápices caulinares enraizados na máxima resposta estimada de $23,3 \mu \mathrm{M}$. A adição de AIB também dobrou a porcentagem de calo, atingindo o ponto de máxima estimado em $22,0 \mu \mathrm{M}$. Esse aumento da porcentagem de calo não pode ser diretamente relacionado à adição de AIB, pois as porcentagens de enraizamento e de calo dos ápices caulinares foram similares em todas as doses de AIB testadas, inclusive

Tabela 1 - Porcentagem de enraizamento e comprimento $(\mathrm{cm})$ de raízes e brotações de ápices caulinares de erva-mate (I. paraguariensis) inoculados em meio $1 / 4$ da concentração dos sais do MS acrescido de diferentes doses de ácido indolbutírico (AIB), com tempos de exposição à auxina de 15 e 30 dias, aos 30 dias de cultivo in vitro.

\begin{tabular}{|c|c|c|c|c|c|c|}
\hline \multirow{2}{*}{$\begin{array}{l}\text { Doses de } \\
\text { AIB }(\mu \mathrm{M})\end{array}$} & \multicolumn{2}{|c|}{------------Enraizamento (\%)------------ } & \multicolumn{2}{|c|}{-----Comprimento das raízes $(\mathrm{cm})$----- } & \multicolumn{2}{|c|}{---Comprimento das brotações $(\mathrm{cm})---$} \\
\hline & 15 dias em AIB & 30 dias em AIB & 15 dias em AIB & 30 dias em AIB & 15 dias em AIB & 30 dias em AIB \\
\hline 0,00 & $37,5 \mathrm{aA}$ & $37,5 \mathrm{bA}$ & $0,45 \mathrm{aA}$ & $0,45 \mathrm{bA}$ & $0,97 \mathrm{aA}$ & $0,97 \mathrm{bA}$ \\
\hline 4,92 & $43,7 \mathrm{aB}$ & $87,5 \mathrm{aA}$ & $0,97 \mathrm{aB}$ & $6,05 \mathrm{aA}$ & $1,00 \mathrm{aA}$ & $1,40 \mathrm{abA}$ \\
\hline 7,38 & $50,0 \mathrm{aB}$ & $87,5 \mathrm{aA}$ & $0,75 \mathrm{aB}$ & $5,80 \mathrm{aA}$ & $0,80 \mathrm{aB}$ & $1,75 \mathrm{aA}$ \\
\hline Média & 43,7 & 70,8 & 0,72 & 4,10 & 0,92 & 1,37 \\
\hline
\end{tabular}

\footnotetext{
${ }^{1}$ Valores seguidos de mesma letra, minúscula para doses de AIB e maiúsculas para tempo de exposição ao AIB, não diferem entre si pelo
} teste de Tukey a $5 \%$ de probabilidade de erro. 
Tabela 2 - Porcentagem de calo e número de raízes e folhas de ápices caulinares de erva-mate (I. paraguariensis) inoculados em meio $1 / 4$ da concentração dos sais do MS acrescidos de diferentes doses de ácido indolbutírico (AIB), com tempos de exposição à auxina de 15 e 30 dias, aos 30 dias de cultivo in vitro.

\begin{tabular}{|c|c|c|c|}
\hline Tratamentos & Calo $(\%)$ & № de raízes & № de folhas \\
\hline \multicolumn{4}{|c|}{ 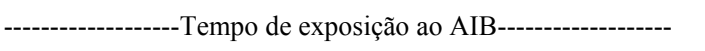 } \\
\hline 15 dias & $64,5 \mathrm{a}$ & $2,8 \mathrm{~b}$ & $5,4 \mathrm{~b}$ \\
\hline 30 dias & $75,0 \mathrm{a}$ & $4,8 \mathrm{a}$ & $6,9 \mathrm{a}$ \\
\hline \multicolumn{4}{|c|}{ Doses de AIB $(\mu \mathrm{M})$} \\
\hline 0,00 & $31,2 \mathrm{~b}$ & $2,6 \mathrm{~b}$ & $6,4 \mathrm{a}$ \\
\hline 4,92 & 90,6 a & $4,6 \mathrm{a}$ & $6,6 \mathrm{a}$ \\
\hline 7,38 & $87,5 \mathrm{a}$ & $4,3 \mathrm{a}$ & $5,4 \mathrm{a}$ \\
\hline Média & 69,8 & 3,8 & 6,1 \\
\hline CV $(\%)$ & 28,7 & 16,0 & 10,8 \\
\hline
\end{tabular}

${ }^{1}$ Valores seguidos de mesma letra não diferem entre si pelo teste de Tukey a $5 \%$ de probabilidade de erro. no tratamento sem a auxina. A adição de AIB ao meio de cultura base também aumentou o número e o comprimento das raízes por explante, atingindo os valores máximos estimados, respectivamente, nas doses de 18,9 e 16,8 $\mu \mathrm{M}$ (Figura 2B).

Os resultados deste experimento estão de acordo com a literatura de que adição de AIB ao meio de cultura aumenta o enraizamento e que altas doses podem afetar negativamente a formação e o crescimento das raízes. A maior porcentagem (86\%) de segmentos nodais de erva-mate enraizaram em meio de cultura com 14,76 $\mu \mathrm{M}$ de AIB (PAULA, 1992). A adição de 4,92 $\mu \mathrm{M}$ de AIB promoveu o enraizamento em $45 \%$ dos explantes de caixeta (Didymopanax morototoni Aubl.), porém o aumento da dose para $7,38 \mu \mathrm{M}$ reduziu essa porcentagem (MANTOVANI, 1997). Em jenipapeiro (Genipa americana L.), doses acima de $9,8 \mu \mathrm{M}$ de AIB diminuíram a quantidade de explantes enraizados, bem como o número e o comprimento das raízes formadas

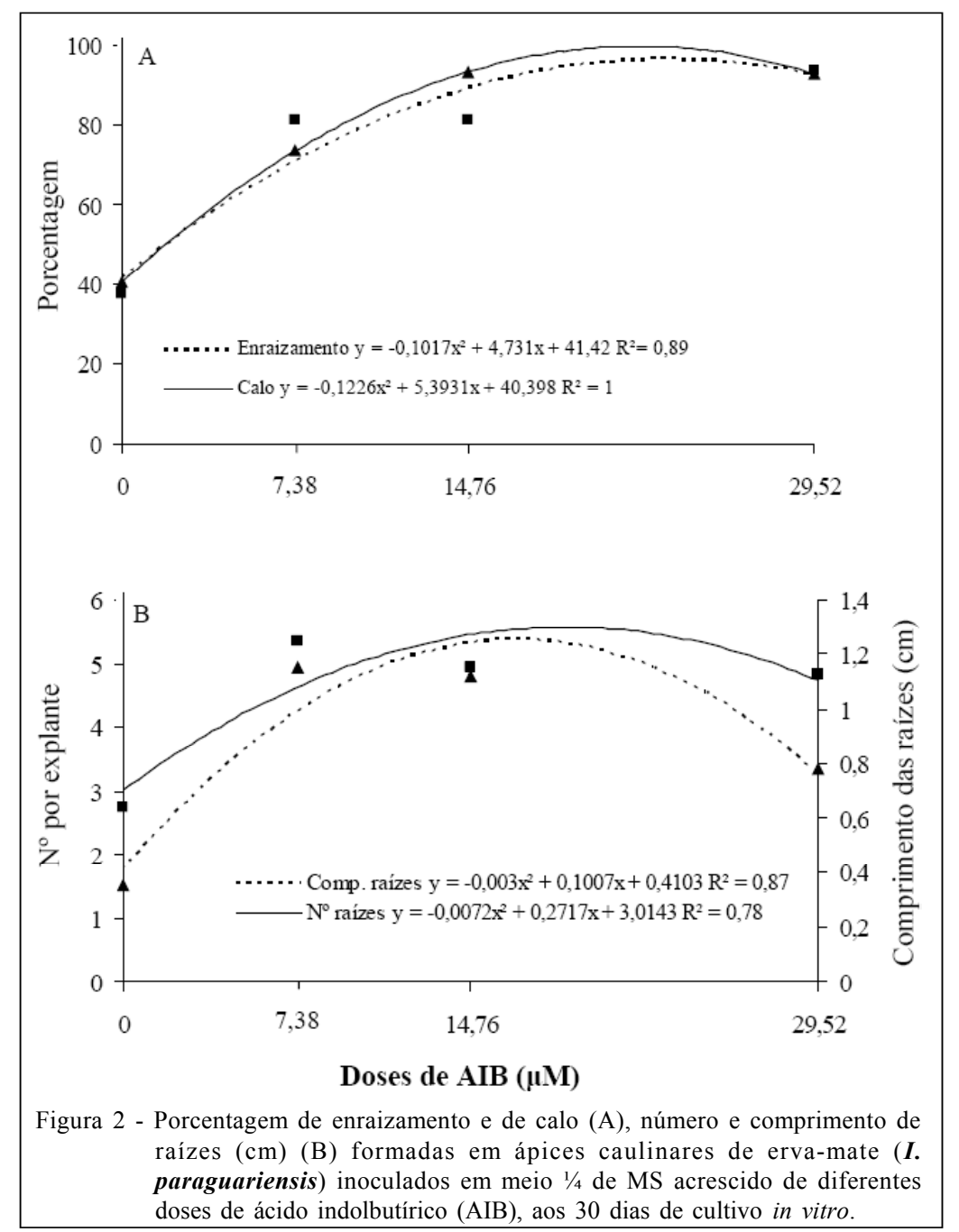

Ciência Rural, v.41, n.1, jan, 2011. 
(Rocha et al., 2008). Elevadas doses de AIB também podem estimular a formação de calos em explantes de erva-mate (Sansberro et al., 1999), o que é geralmente indesejável por prejudicar as conexões vasculares (FACHINELLO et al., 1995) e reduzir a sobrevivência das plantas durante a aclimatização (MAJADA et al., 2000).

O aumento da dose de AIB ao meio de enraizamento in vitro de ápices caulinares de erva-mate diminuiu a sobrevivência e aumentou a porcentagem de calo durante a aclimatização das plantas de ervamate (Figura 3A). O aumento da dose de AIB no meio de enraizamento in vitro aumentou a porcentagem de enraizamento, o número de raízes e a alturas das plantas de erva-mate aclimatizadas por 60 dias, respectivamente até as doses estimadas de 13,5; 16,5 e 16,8 $\mu \mathrm{M}$ de AIB (Figuras 3A e 3B). Portanto, o aumento da dose de AIB no meio de enraizamento in vitro aumentou a porcentagem de calo, sendo que a dose de $7,38 \mu \mathrm{M}$ de AIB foi a mais equilibrada em termos de porcentagens de sobrevivência, de enraizamento e de calo e atingiu a porcentagem estimada de enraizamento de $94 \%$. Considerando que altas porcentagens de calo afetam a sobrevivência das plantas durante a aclimatização (MAJADA et al., 2000), sugere-se que o enraizamento in vitro de ápices caulinares de erva-mate seja realizado em meio de cultura base acrescido de 7,38 $\mu \mathrm{M}$ de AIB.

Neste trabalho, explantes assépticos foram produzidos a partir de embriões zigóticos imaturos com excelente resposta morfogênica, devido à alta juvenilidade e capacidade de brotação que apresentam. A adição de $8,88 \mu \mathrm{M}$ de BAP ao meio com $1 / 4$ da concentração dos sais do MS promoveu um aumento do número e do comprimento das brotações

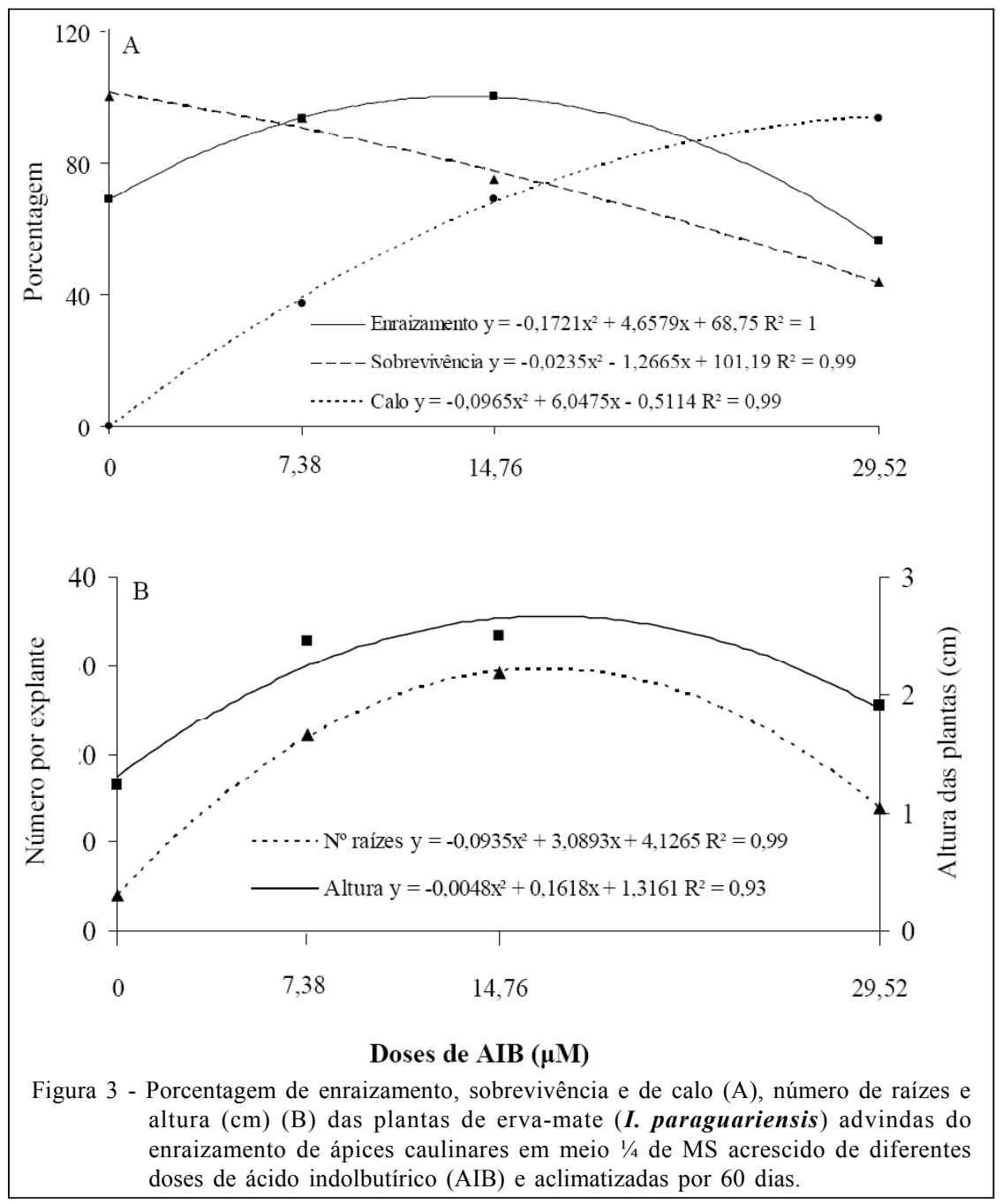

Ciência Rural, v.41, n.1, jan, 2011. 
adventícias, o que favoreceu a multiplicação. Essas brotações enraizaram em 30 dias de cultivo em meio de cultura base acrescido de $7,38 \mu \mathrm{M}$ de $\mathrm{AIB}$ e, quando aclimatizadas em câmara de crescimento e casa de sombra, apresentaram uma alta porcentagem de sobrevivência e de enraizamento, resultando em plantas de alto vigor. Outros experimentos de enraizamento de ápices caulinares devem ser conduzidos, pois explantes de Ilex aquifolium L. foram mais eficientemente enraizados ex vitro do que in vitro (MAJADA et al., 2000), o que facilitaria a produção de plantas de ervamate. Portanto, a micropropagação de plântulas oriundas de embriões zigóticos imaturos pode ser utilizada tanto para a produção de plantas de alto vigor e qualidade fitossanitária quanto para a formação de microjardim clonal, visando à produção em larga escala de mudas de erva-mate.

\section{REFERÊNCIAS}

CARVALHO, P.E.R. Espécies arbóreas brasileiras. Brasília: Embrapa Informação Tecnológica, 2003. V.1, 1039p.

DUTRA, L.F. et al. Introdução ao cultivo in vitro de ervamate (Ilex paraguariensis). Colombo: Embrapa Florestas, 2008. 33p. (Boletim de Pesquisa e Desenvolvimento 38).

FACHINELLO, J.C. et al. Propagação de plantas frutíferas de clima temperado. 2.ed. Pelotas: UFPel, 1995. 178p.

FICK, T.A. et al. Estabelecimento e crescimento in vitro de plântulas de louro-pardo. Ciência Florestal, v.17, n.4, p.343349, 2007. Disponível em: $<\mathrm{http}: / / \mathrm{www} . u f s m . b r /$ cienciaflorestal/ artigos/v17n4/A6V17N4.pdf>. Acesso em: 31 mar. 2010.

FOWLER, A.J.P.; STURION, J.A. Aspectos da formação do fruto e da semente na germinação da erva-mate. Colombo: Embrapa Florestas, 2000. p.1-5. (Comunicado Técnico n.45). Disponível em: $<$ http://www.cnpf.embrapa.br/publica/comuntec/ edicoes/com_tec45.pdf>. Acesso em: 30 out. 2010.

HU, C.Y. Holly (Ilex spp.). In: BAJAJ, Y.P.S. (Org.). Biotechnology in agriculture and forestry 5: trees II. Berlin: Springer-Verlag, 1989. V.5, 622p.

HU, C.Y.; FERREIRA, A.G. Cultura de embriões. In: TORRES, A.C.; CALDAS, L.S. (Org.). Técnicas e aplicações da cultura de tecidos de plantas. Brasília: Embrapa-CNPH, 1998. 509p.

KITTO, S.L. Comercial micropropagation. HortScience, v.32, n.6, p.1012-1016, 1997.

MAJADA, J.P. et al. Micropropagation of Ilex aquifolium L. In Vitro Cellular \& Developmental Biology Plant, v.36, p.521526, 2000. Disponível em: <http://www.ingentaconnect.com/ content/klu/ivp/2000/00000036/00000006/00000093>. Acesso em: 31 mar. 2010.

MANTOVANI, N.C. Estudo da regeneração in vitro de caixeta Didymopanax morototoni (Aubl.) Dene. Et Planch. 1997. 106f. Dissertação (Mestrado em Engenharia Florestal) - Universidade Federal de Santa Maria, Santa Maria, RS.
MOREIRA-DIAS, J.M. et al. Daylength and photon flux density influence the growth regulator effects on morphogenesis in epicotyl segments of Troyer citrange. Scientia Horticulturae, v.87, p.275-290, 2001. Disponível em: <http://www.sciencedirect.com/ s c i ence?_ob=A r t i c le URL\&_udi=B 6 T C 3 $428 \mathrm{FK} 543 \&$ user $=10 \&$ coverDate $=03 \% 2 \mathrm{~F} 12 \% 2 \mathrm{~F} 2001 \&$ rdoc $=1 \&$ fmt $=$ high $\&$ orig $=$ search\&_sort $=\mathrm{d} \&$ docanchor $=\& \mathrm{view}=\mathrm{c} \&$ searchStrId $=1276997686 \&$ rerunOrigin $=$ google $\& \_$acct $=$C0000502 $21 \&$ version $=1 \&$ urlVersion $=0$ \&_userid $=10 \& \mathrm{md} 5=80 \mathrm{ca} 1924 \mathrm{~b} 3 \mathrm{ff} 055$ 57f5950c460115b90 >. Acesso em: 31 mar. 2010. doi: 10.1016/ S0304-4238(00)00186-2.

MURASHIGE, T.; SKOOG, F. A revised medium for rapid growth and bioassays with tobacco tissue cultures. Physiologia Plantarum, v.15, n.3, p.473-497. 1962.

PAIVA, R.; OLIVEIRA, L.M. de. Fisiologia e produção vegetal. Lavras: UFLA, 2006. 104p.

PAULA, S.R. de. Micropropagação de erva-mate (Ilex paraguariensis St. Hil.) e comparação das folhas de plantas in vitro com as originadas em casa de vegetação. 1992. 74f. Dissertação (Mestrado em Botânica) - Universidade Federal do Paraná, Curitiba, PR.

ROCHA, M.A.C. da et al. Enraizamento in vitro e aclimatização de genótipos de jenipapeiro (Genipa americana L.). Revista Brasileira de Fruticultura, v.30, n.3, p.769-774, 2008. Disponível em: <http://www.scielo.br/scielo.php?pid=S0100$29452008000300035 \&$ script $=$ sci abstract $\&$ tlng $=p t>$. Acesso em: 30 mar. 2010 . doi: 10.1590/S0100-29452008000300035.

SANSBERRO, P.A. et al. In vitro culture of rudimentary embryos of Ilex paraguariensis: responses to exogenous cytokinins. Journal Plant Growth Regulation, v.17, p.101-105, 1998. Disponível em: <http://www.springerlink.com/content/kgrcgbgdvmwl6xgg/>. Acesso em: 30 mar. 2010. doi: 10.1007/PL00007014.

SANSBERRO, P. et al. In vitro plant regeneration of Ilex paraguarienses (Aquifoliaceae). In Vitro Cellular \& Developmental Biology Plant, v.35, p. 401-402, 1999. Disponível em: <http://www.ingentaconnect.com/content/klu/ ivp/1999/00000035/00000005/00000054>. Acesso em: 30 mar. 2010. doi: 10.1007/s11627-999-0054-5.

STURION, J.A. Produção de mudas e implantação de povoamentos com erva-mate. Curitiba: EMBRAPA/CNPF, 1988. 12p. (Circular Técnica, n.17). Disponível em: $<$ http:/ /www.cnpf.embrapa.br/publica/circtec/edicoes/circ-tec17.pdf>. Acesso em: 30 out. 2010.

WENDLING, I. Propagação vegetativa de erva-mate (Ilex paraguariensis): estado da arte e tendências futuras. Colombo: Embrapa Florestas, 2004. 46p. (Documentos n.91). Disponível em: <http://www.cnpf.embrapa.br/publica/seriedoc/ edicoes/doc91.pdf>. Acesso em: 30 out. 2010.

ZANIOLO, S.R.; ZANETTE, F. Micropropagação de ervamate a partir de segmentos nodais. Scientia Agraria, v.2, n.1-2, p.39-44, 2001. Disponível em: <http://dialnet.unirioja.es/ servlet $/$ articulo? codigo $=2913254>$. Acesso em: 31 mar. 2010 .

ZANON, A. Produção de sementes de erva-mate. Curitiba: EMBRAPA/CNPF, 1988. 8p. (Circular Técnica, n.16). Disponível em: <http://www.cnpf.embrapa.br/publica/circtec/ edicoes/circ-tec16.pdf>. Acesso em: 30 out. 2010. 